\title{
Aristocratismo y razón en Gonzalo Fernández de la Mora
}

\author{
Aristocratism and Reason in Gonzalo Fernández \\ de la Mora
}

\author{
Carlos GoÑI APESTEGUÍA \\ Universidad de Navarra \\ goni85@hotmail.com
}

Recibido: 25/03/2013

Aceptado: 20/02/2014

\section{Resumen}

Gonzalo Fernández de la Mora construyó una interesante teoría centrada en la composición aristocrática de toda sociedad. Su elitismo está basado en argumentos racionales, más todavía, está basado en el uso de la razón. Esta teoría trata de refutar los discursos igualitarios, mostrar el carácter disfuncional de las ideologías y la falsedad de legitimaciones morales de la democracia. La democracia es, en este punto, nada más que una forma de seleccionar elites políticas.

Palabras clave: Ideologías, elites, aristocracia, Razonalismo, democracia.

\begin{abstract}
Gonzalo Fernández de la Mora built an interesting theory dealing with the aristocratic composition of every society. His elitism is based on racional arguments, even more, it is based on the use of reason. This theory tries to refute igualitarian discourses, show the dysfunctional caracter of ideologies and the falsehood of moral legitimations of democracy. Democracy, in this point, is no more than a way to select political elites.

Keywords: Ideologies, elites, aristocracy, Razonalismo, democracy.
\end{abstract}


Gonzalo Fernández de la Mora (1924-2002) puede ser considerado uno de los autores de teoría política más influyentes de la segunda mitad del siglo XX español, especialmente en cuanto al pensamiento conservador se refiere. Si bien, se trata como ha señalado Pedro Carlos González Cuevas de un "conservador heterodoxo" en España ${ }^{1}$. Su obra, pese a todo, se sitúa en la misma línea en que lo hacen la larga pléyade de autores conservadores españoles partidarios de la defensa de la constitución elitista de toda agrupación humana como un dato fáctico se refiere. Sin embargo, su postura también en este punto es ciertamente original. Apoyado en un sistema filosófico sobre el que reclamó originalidad, el Razonalismo ${ }^{2}$, Fernández de la Mora construye toda su doctrina filosófico-política. Este sistema, expuesto a partir de la fundación de su revista Razón Española en 1983, resulta esencial para entender la tesis expuesta en su obra más polémica y conocida El crepúsculo de las ideologías, pese a que esta conexión ha sido frecuentemente soslayada con la consiguiente degradación comprensiva de su obra. En el quicio de ambos, sistema y tesis, se encuentra su concepción elitista de la sociedad.

El aristocratismo de Fernández de la Mora tiene una doble vertiente. Por un lado, se podría hablar de una dimensión antropológica del aristocratismo según la cual la desigualdad y gradación es consustancial a los seres humanos. Se trata de una descripción fáctica de la vida humana. Por otro lado, hay una dimensión sociológica ya que la tesis de Fernández de la Mora se inscribe en una revalorización de la jerarquía, en una aceptación por parte de las masas de la desigualdad y la aparición de ciertas aristocracias. Ambas dimensiones contribuyen a una crítica de la ideología que las ignora y que continua siendo un producto para consumo masivo en una realidad y un tiempo que es eminentemente jerarquizado ${ }^{3}$.

Una descripción y análisis de la doctrina aristocrática, por tanto, no sirve sólo para exponer una de las muchas doctrinas de la elite que surgieron del conservadurismo español sino que mostrará la imbricación con el concepto de razón y su incompatibilidad con la ideología.

\footnotetext{
${ }^{1}$ Según este autor la heterodoxia de Fernández de la Mora se quintaesencia en la defensa de valores tradicionalmente conservadores desde una aceptación de la modernidad filosófica y la secularización intelectual. Cfr. P.C. González Cuevas, Conservadurismo heterodoxo, Madrid, Biblioteca Nueva, 2009, pp. 134-135.

${ }^{2}$ Para un resumen de las líneas centrales de este sistema filosófico ver: C. Goñi Apesteguía, "El razonalismo en Gonzalo Fernández de la Mora”, Razón Española, 172, 2012, pp. 171-198.

${ }^{3}$ Nótese que para Fernández de la Mora, al igual que para Ortega, la jerarquía no es meramente política, aunque considera que se está produciendo un fenómeno de cierta asimilación.
} 


\section{Notas del aristocratismo razonalista}

Fernández de la Mora considera que la naturaleza es netamente anti-igualitaria. La dotación de cada individuo es diversa y graduada y de ahí la conclusión de una diferenciación esencial. La igualdad humana ha sido un falso anhelo que se ha dado tanto en el plano religioso como en el económico y político. Sin embargo, lo cierto es que la desigualdad es la estructura habitual de lo real. La realidad se nos muestra compuesta por entes individuales diferenciables entre sí y que, además, se estructuran según la superioridad e inferioridad de cada uno. La realidad no se da igualitariamente sino que es la razón la que operando sobre lo real realiza síntesis igualadoras que, consecuentemente, no son reales sino que constituyen el modo de operar de la razón, se trata de una "maravilla de economía mental"4. A esta desigualdad dada en el carácter no idéntico de cada individuo, que denomina metafísica, se le unen la física y la zoológica.

Esta constitución desigual de lo real afecta a todo el universo ontológico. Sin embargo, Fernández de la Mora centra sus análisis en la especie humana. Así, desarro1la, tres desigualdades intraespecíficas.

En primer lugar, Fernández de la Mora apela a la genética como una fuente inagotable de desigualdad. Incluso las diferencias en las funciones superiores, intelectuales, pertenecen herencia genética y resultan "en gran medida, inmutables" cierto, es que la distribución del cociente intelectual forma parte de la dotación genética y conforma un abanico de desigualdades y éstas establecen una elite o minoría intelectual, al menos en el punto de partida ${ }^{6}$. La dotación intelectual está desigualmente distribuida entre los individuos pero, además, dado que ésta está fuertemente determinada por la herencia genética, resulta que aparecen individuos o grupos intelectualmente privilegiados ${ }^{7}$.

En segundo lugar, existe una diferente herencia noética. Por herencia noética entiende Fernández de la Mora la peculiar estructura de la aprehensión humana. El modo

\footnotetext{
4 "La realidad es un torrente diversificador, y la mente una represa canalizadora. En el universo no hay más igualitarismo que el lógico impuesto por la razón, y el ético dictado por la voluntad. Filosóficamente, la igualdad es una ficción mental fundada en ciertas semejanzas estructurales y funcionales. Todo lo real es desigual en el sentido de que no hay dos cosas idénticas, de que cambian, y de que en algún modo unas son superiores o inferiores a otras". G. Fernández de la Mora, La envidia igualitaria, Barcelona, Planeta, 1984, p. 171.

${ }^{5}$ Ibidem, p. 180.

6 "El reparto de la capacidad mental es, pues, rotundamente dispar, y crea una masa más o menos desposeída y una pequeña minoría intelectualmente privilegiada. Donde el postulado del igualitarismo humano queda más duramente desmentido es en la dimensión más característica del homo sapiens, la que condiciona el destino personal y el servicio a la especie: la inteligencia”. Ibidem, p. 181 . ${ }^{7}$ Cf. ibidem, p. 183.
} 
en que el hombre tiene de aproximarse y conocer lo real es radicalmente diferente a la de cualquier otra especie. Pero, al margen de esta diferencia interespecífica, señala el autor una diferencia intraespecífica. Hay individuos que, en opinión de Fernández de la Mora, ven el universo de manera distinta a como lo hacen el resto de individuos de la especie ${ }^{8}$. Todos los seres humanos tienen una estructura similar en su aproximación al mundo, sin embargo, se observa que hay ciertos individuos que varían esta aproximaciones, se trata de "matices", como señala el propio autor, pero que demuestra la variabilidad y diferencias entre los distintos individuos de la especie.

En tercer lugar, existe una desigualdad, que Fernández de la Mora denomina, "vital" aunque cabría llamarla también "felicitaria". Esta diferencia intraespecífica e interindividual se basa en las diferentes vías, u objetivos, en los que cada uno sitúa la satisfacción de la búsqueda de la felicidad. Se trata de una desigualdad sobrevenida, es decir, generada por los propios hombres, en el que juega un papel fundamental la voluntad. Esta diferencia electiva muestra como no hay dos existencias personales iguales, todas son radicalmente diferentes. Se trata de una extensión de la radical desigualdad genética que se acentúa con el transcurso de la vida y que no sólo la amplía sino que complica el básico factor diferencial biológico?.

En cuarto lugar, Fernández de la Mora aborda la "desigualdad ultraterrena" afrontando la igualación que supone el cristianismo respecto de otras religiones. Considera el autor que pese a que en el cristianismo haya una llamada universal a la santidad hay diferencias sustanciales. Para demostrar estas diferencias apela a la gracia divina que no es concedida igualitariamente. La diversidad de gracias es un importante factor de desigualdad religiosa. Incluso en la otra vida hay diferencias ya que, citando el Concilio de Florencia, Fernández de la Mora apuntilla que la visión beatífica no es igual para todos, hay una gradación en la perfección de la contemplación divina. La libertad divina para la concesión de sus gracias y los méritos adquiridos por cada uno establecen una desigualdad en el plano ultraterreno ${ }^{10}$.

Por último, está la desigualdad social que resulta, al efecto de lo aquí analizado, la más relevante y a la que Fernández de la Mora dedica más páginas en su enumeración de las desigualdades. Se trata de las desigualdades derivadas de la convivencia social del hombre, de su vivir con otros individuos y organizarse con ellos. La organización en sociedad conlleva dos jerarquizaciones. Por un lado, la relativa al

\footnotetext{
${ }^{8}$ Cf. ibidem, p. 187.

9 "El carácter dinámico de la vida humana duplica la individualidad genética, y la complica con las infinitas variantes de la libertad o, por lo menos, de las circunstancias. Para el hombre ser es vivir, y porque quiere vivir se hace desigual". Ibidem, p. 193.

10 "El igualitarismo cristiano se limita a ofrecer a todos, sin excepción, la condición de hijos de Dios y la oportunidad de salvarse; pero, luego, el libre arbitrio divino en la adjudicación de dones y la aplicación de una justicia proporcional a las conductas desembocan en el desigualitarismo". Ibidem, p. 194.
} 
saber. En sociedad se produce una jerarquización relativa al grado de conocimiento. La aceptación de un diferencial de conocimiento, de la superioridad cognoscitiva de ciertos individuos, conlleva la aceptación de sus afirmaciones y sus consejos. Esta autoridad científica y moral produce una ignorancia relativa ${ }^{11}$ de quienes aceptan el argumento de autoridad, es decir, de quienes aceptan la superioridad de ciertos individuos en un ámbito determinado. Ignorancia que, como se verá, no tiene un matiz peyorativo sino que responde a una necesidad de economía intelectual. En segundo lugar, está el poder que por su necesidad de coerción, su egocentrismo y su delegabilidad es menos noble que la autoridad ${ }^{12}$. El poder marca una línea divisoria entre aquellos que lo ejercen directamente y aquellos que lo padecen, o que son objeto de la acción del poder y no sujeto de su ejercicio, es decir, en toda sociedad hay gobernantes y gobernados ${ }^{13}$. El grado en el que se ejerza el poder es también, un elemento de desigualdad. Esta diversidad de participación en el poder está relacionado, además, con la especialización de funciones ya que el ejercicio del poder por parte de unos, y su alienación para otros, es prueba de esta estancamiento de las funciones que, en el mejor de los casos, se da por criterios aptitudinales.

Así pues, la condición social del hombre y su organización en una comunidad política implica la aparición de variados factores de desigualdad.

"En suma, una comunidad política implica normas, y por tanto jerarquía, coacción y valoración del mérito, o sea, desigualdades en posición, en fuerza y en bienes. Implica la división de funciones y, por tanto, diferencias de estimación y de competencia. Todas estas disparidades intrínsecas a la comunidad política se traducen en desigualdades de poder" ${ }^{14}$.

La desigualdad, y la jerarquización inherente a la configuración comunitaria es un hecho. Fernández de la Mora, opina que no hay sociedad sin jerarquía, no hay sociedad sin separación. Las masas, los pueblos, nunca se gobiernan a sí mismos, por imposibilidad, así que tiene que haber una elite dirigente ${ }^{15}$. En toda sociedad hay una división entre las elites dirigentes y las masas gobernadas. Por supuesto, y siguiendo a Ortega, para Fernández de la Mora, las elites no se dan exclusivamente en el campo

\footnotetext{
${ }^{11}$ Es lo que denomina Fernández de la Mora un tipo de irracionalidad subjetiva que, sin embargo, es objetivamente racional al haber llegado la autoridad, en cuestión, a la objetividad del aserto. Cf. G. Fernández de la Mora, "La razón aceleradora" en Razón Española, 69, 1995, p. 5.

${ }^{12}$ Cf. op. cit., p. 188.

${ }^{13}$ Cf. ibidem, p. 191.

${ }^{14}$ Ibidem, pp. 191-192.

15 "La autenticidad de la democracia inorgánica es muy problemática. Se define como el gobierno del pueblo por el pueblo; pero, de hecho, el pueblo no gobierna jamás en una gran nación; siempre es gobernado por una élite”. G. Fernández de la Mora, El Estado de obras, Madrid, Doncel, 1977, p. 31.
} 
político. Lo cierto es que en todo ámbito hay ciertas elites que se erigen en directoras del ámbito en cuestión ${ }^{16}$.

El factum de la configuración elitista de la sociedad, sin embargo, no es un tema exclusivamente de reconocimiento por parte de las masas. Es decir la autoridad conferida a la elite, no es, siguiendo la sentencia clásica, exclusivamente un saber socialmente reconocido. El aristocratismo tiene como referente objetivo, el uso de la razón de tal manera que ese es el fundamento de su elitismo. Es decir, forman parte de la elite aquellos sujetos caracterizados por una excelencia en el uso de la razón.

\section{La razón: referente objetivo de la aristocracia}

El hombre tiene en la razón su factor diferenciador con respecto al resto de especies animales, lo propio en el actuar humano es que éste se guía por una decisión racional ${ }^{17}$. La razón diferencia al hombre de las demás especies pero, al mismo tiempo, es el principal elemento de distinción intraespecífica. El ejercicio de la razón es el factor diferenciador de la minoría respecto a la masa. La razón es un factor, el principal factor, aristocratizante entre los seres humanos. La racionalidad de cada sujeto, su empleo en el ejercicio de la razón, sea cual sea el campo al que ésta se aplica, es un factor diferenciador que va configurando dos clases. Asimismo la creciente complejidad de la existencia ${ }^{18}$ contribuye a que las diferencias entre quienes cultivan la razón y no lo hacen sea cada vez mayor. Se puede establecer una relación directa entre densidad racional de las sociedades, es decir, cantidad y dependencia de los productos culturales y científicos, y aristocratización merced a la razón. Cuanto más racionalizada está la vida cotidiana de un grupo humano mayor distancia toma la minoría respecto de la masa, que cada vez resulta más dependiente respecto de aquella.

"La razón es la nota que diferencia a la especie humana de todas las terrestres; pero esa nota es tanto más aristocrática y escasa cuanto más intensa; es conceptualmente

\footnotetext{
16 "En las comunidades políticas históricas no se ha dado ni el gobierno de uno solo, ni el de todos. Las más autocráticas de las monarquías han tenido magistrados con parcelas de poder. En los más populistas de los municipios ha habido una minoría que ha administrado. Sólo hay una forma real de gobierno, la oligarquía, entendida en su sentido etimológico como mando de unos pocos. En todas las áreas de la convivencia aparece una élite que decide el rumbo dominante, lo mismo en la comunidad religiosa, científica o artística que en la propiamente política”. G. Fernández de la Mora, "Contradicciones de la partitocracia", Razón Española, 49, 1991, p. 156.

17 "Lo propio del hombre superior es la decisión altamente racionalizada en el área de su competencia”. G. Fernández de la Mora, "Razón y arbitrariedad", Razón Española, 22, 1987, p. 132.

${ }^{18}$ Los cambios en la sociedad han producido la aparición de un nuevo modelo el "post-industrial" uno de cuyos grandes analistas, Daniel Bell, denomina a la centralidad del conocimiento en esta sociedad emergente "axial principle". D. Bell, The Coming of Post-industrial Society, New York, Basic Books, 1973, p. 14.
} 
homogeneizadora, pero realmente estratificante. El desigualitarismo racional de la Humanidad tiende a aumentar entre el hombre medio y los razonadores. Además, la complejidad tecnológica de la vida moderna nos va haciendo más dependientes de los expertos desde la electrónica a la medicina o la economía. Los que saben resolver un problema aparecen cada vez más distantes y excelsos"19.

Dependencia que resulta recíproca ya que también la masa es condición de posibilidad para la aparición de la elite razonadora. Para que surjan estos individuos egregios es fundamental el concurso de las grandes masas para realizar las funciones más biológicas. Es decir, la minoría no puede surgir en un contexto en el que las necesidades materiales básicas no están satisfechas. Las masas con su labor aseguran la continuidad y aparición de la minoría. Otra función de la masa a este respecto es, señala Fernández de la Mora en claros términos biológico-funcionales, la de perpetuar la especie garantizando un número de individuos suficiente para garantizar la aparición de aquellos destinados a formar parte de la minoría ${ }^{20}$.

Las tendencias que contribuyen a acentuar esta tendencia a la bipolarización son tres. En primer lugar, está la escasa proclividad de la masa al uso de la razón. Las masas, como ya se ha indicado, son reticentes al uso de argumentaciones racionales. La falta de voluntad respecto del uso de la razón de las masas aumenta el diferencial respecto de las minorías razonadoras ${ }^{21}$. El hombre medio se resiste al cultivo de la razón y así aristocratiza a quien dedica su vida a esta labor. La regla de la "economía del esfuerzo" contribuye a proporcionar una mayor autoridad a los expertos a los que la masa encomienda su vida ${ }^{22}$. A esta tendencia connatural a la masa, se une la demanda cada vez mayor de productos de la investigación científica. La escasa dedicación y creciente dependencia de las masas respecto de las minorías razonadoras contribuye a la aristocratización de la razón ${ }^{23}$.

El segundo factor, que contribuye a la ampliación de las diferencias entre la minoría y la masa con la razón como factor objetivo es la creciente cantidad de información. Este factor produce una aristocratización negativa. En opinión de Fernández

\footnotetext{
${ }^{19}$ G. Fernández de la Mora. “Aristocratismo de la razón”, Razón Española, 62, 1993, p. 260.

20 "La naturaleza es elitista y por eso prima a los mejores y selectos; pero también necesita a los grandes números para asegurar la continuidad de las especies y aumentar la posibilidad de los individuos alfa o superiores". G. Fernández de la Mora, El hombre en desazón, Oviedo, Nobel, 1997, p. 345.

${ }^{21}$ Como se ha indicado con anterioridad. A la diferente dotación intelectual se suma la inhibición de las masas.

22 "La inmensa mayoría de los humanos se conduce según un principio subjetivo de economía del esfuerzo: los mejores resultados con el mínimo trabajo. Esto conduce a utilizar los hallazgos de los razonadores no por propio raciocinio sino por tradición o por la autoridad de los expertos". Op.cit., p. 257.

${ }^{23}$ Ibidem, p. 258.
} 
de la Mora el flujo de información ha crecido y, por ello, las masas se encuentran perdidas ante el aluvión de datos, interpretaciones y hechos. La respuesta ante este hecho, por parte del hombre medio, es un "escepticismo genérico". Por tanto, el incremento de información, debido principalmente al enorme desarrollo de la ciencia y, más aún, a los medios de comunicación ${ }^{24}$ es tanto un factor posibilitador del uso de la razón, para las minorías cuyo acceso a los productos racionales es facilitado, como dificultador, ya que promueve el escepticismo y la "irracionalidad media" 25 .

El tercer factor que acentúa la aristocratización racional es el especialismo. La parcelación y exhaustividad de los saberes provoca la separación del experto respecto de los demás individuos es, por tanto, un elemento aristocratizador. Ortega ya había atendido a este fenómeno al que había denominado "La barbarie del especialismo" y al científico moderno un "bárbaro moderno" o "un sabio ignorante" cuyo mayor riesgo es actuar como minoría allá donde es masa, es decir, cuando sale de su "mínimo rincón del universo" 26 . Un análisis similar es el esgrimido por Fernández de la Mora quien afirmaba también que la especialización es una "pseudobarbarie". Sin embargo, considera que este fenómeno es necesario para el avance de la ciencia y, por tanto, no puede valorarse negativamente, como hace Ortega. Así lo afirma en un texto con un claro regusto orteguiano pero notablemente más optimista que en los dedicados al tema en el maestro madrileño.

"La masa de letra impresa y el volumen de conocimientos han crecido tan rápidamente en el último siglo, que se ha impuesto la especialización. Cada día es más difícil la filosofía y la síntesis. La división del trabajo intelectual es una obligada pseudobarbarie, y la forzada atomización de los saberes y de los métodos tiene filisteas consecuencias en la concepción del mundo. Quizá las más graves sean las contradicciones y los autonomismos y, consecuentemente, un cuarteamiento de los cimientos doctrinales que conduce a la angustia y al escepticismo. Siempre hay una correlación histórica y aún metafísica entre lo posible y lo necesario. Ahora esta correlación es singularmente obvia. La mecanización de la información no es ya un

\footnotetext{
${ }^{24}$ Esta valoración de los medios de comunicación no implica una crítica. En 1965 polemizó con Juan de Alcalá que desde las páginas de Pueblo de 28-IX-1965, en la tribuna "Dar que hablar" señaló que la televisión posibilitaba un mayor dominio a los ideólogos. Es decir, los medios de comunicación serían un medio de dominación más que de racionalización. Respondió Fernández de la Mora con artículo en la misma publicación fechado el 3-XII-1965 defendiendo que los medios de comunicación ponían a la luz los defectos argumentativos del retórico. También en El crepúsculo de las ideologías señalaba que los medios de comunicación son un factor desideologizador y, por tanto, racionalizador. G. Fernández de la Mora, El crepúsculo de las ideologías, Madrid, Espasa-Calpe, 1986, p. 154.

${ }^{25}$ Op. cit., p. 259.

${ }^{26}$ J. Ortega y Gasset. La rebelión de las masas, Madrid, Austral, 2007, pp.170 y ss.
} 
avance más o menos cómodo y espectacular de la técnica, es una necesidad para que continúe eficazmente el progreso científico del género humano. Se anuncia en lotananza una etapa sin infolios ni eruditos, una época de investigadores empíricos y meditadores puros, de hallazgos mondos y de totalitarias síntesis; en suma, una coyuntura cenital, optimista y creadora para el logos" 27 .

La especialización es la vía que la razón tiene de avanzar a través de su principal producto, que es la ciencia. Por tanto, la barbarie individual que supone la especialización, en tanto que el sujeto es ignorante respecto de gran cantidad de ámbitos humanos, sin embargo, es un fenómeno habitual y aún necesario. Así la barbarie en términos individuales se convierte en elevación de la especie.

La valoración positiva de la especialización por su apelación al bien de la especie no excluye, sin embargo, un juicio moral de los individuos pertenecientes a la minoría. Al igual que en Ortega a estos sujetos, a las minorías, Fernández de la Mora les atribuye ciertas connotaciones de decisión ética, es decir, de voluntad de ser más. La razón está sometida a la voluntad y de ahí que requiera de un acto de la voluntad para ponerse en marcha. El camino de la razón es un camino arduo y sometido a la voluntad, es una vía costosa y áspera ${ }^{28}$. El individuo que toma partido por la razón, que dedica su vida a su cultivo, elige un camino duro alejado de la inercia y el pragmatismo de la masa. No en vano, lo característico de las aristocracias es tener ideas y su virtud principal el coraje $\mathrm{e}^{29}$.

Además, la eticidad de la minoría viene por el hecho de que el desarrollo de la razón, que es su labor propia, es moralmente deseable para la especie. El imperativo específico hace que todo avance de la razón sea un bien para la especie y, por tanto, un impulso ético teniendo en cuenta que para Fernández de la Mora, la especie se erige en criterio de moralidad. La postergación de los mejores, es decir, la ruptura del paradigma aristocrático, resulta inmoral ya que se elimina a los cultivadores del principal instrumento que tiene el hombre para el perfeccionamiento e incremento de sus capacidades. Este paradigma, el de "la especie como moral", indica, además, que la especie humana cuenta con unos individuos que son los razonadores, es decir, la aristocracia, y que se erigen en portavoces de la especie ${ }^{30}$.

\footnotetext{
${ }^{27}$ G. Fernández de la Mora, "El crepúsculo de los eruditos”, ABC de 4-V-1963.

28 "Pero hay tareas que sólo son auténticas si se cumplen poniendo entre paréntesis todos los vientos, y una de ellas es la teoría. Obstáculo serio y áspero: aunque óptimo para medir calidades". G. Fernández de la Mora, "Los mansos", $A B C$ de 20-II-1965.

${ }^{29}$ G. Fernández de la Mora, "Versatilidad", $A B C$ de 13-VIII-1978.

30 "La especie tiene sus portavoces que son los moralistas, los científicos y los gobernantes, y su común instrumento para enunciar preceptos es la razón”. Op. cit., p. 215.
} 
El factor diferencial de la aristocracia en Fernández de la Mora es el uso de la razón, dependiendo de la gradación en su uso los individuos se jerarquizan. Sin embargo, de entrada hay ya un punto de partida diferencial entre las dos clases, minorías y masas, cuya relación con el concepto de razón es obvio. Es minoría aquel que crea cultura mientras que es masa aquel que la consume. La cultura, prótesis adaptativa del hombre, es creada por unos pocos individuos y no por la masa de hombres medios. La elevación de nivel que supone la cultura, tiene una autoría limitada ${ }^{31}$. Así pues, la labor propia de la minoría intelectual es marcar "las posiciones creadoras" 32 .

"La inmensa mayoría de la Humanidad no es creadora, sino consumidora de cultura. La punta de lanza de la razón la empuñan sólo unos pocos. Esa élite no es promovida por la masa, sino que se selecciona a sí misma como consecuencia del azar cromosómico y también del ambiental porque la simiente que cae en la duna ni arraiga ni fructifica" ${ }^{33}$.

La racionalización de la existencia humana sólo puede venir por la capacidad creadora de esta minoría razonadora ${ }^{34}$. No se puede aspirar a que todos los sujetos sean subjetivamente racionales, es decir, tomen todas las decisiones dependiendo de criterios estrictamente racionales y después de una especulación crítica. Las masas siempre serán consumidoras de cultura y consumirán tanta y de tal calidad como sea capaz de generar la minoría.

La acción propia de las masas es el consumo. Las masas se inhiben del duro ejercicio racional, de la dedicación a la creación cultural y racional. Pero esta abdicación de la condición racional no implica que el hombre medio pueda vivir sin estos productos de la razón generados por las elites. Por eso necesita que las minorías razonadoras ejerzan como tal y exploten la capacidad creadora de la razón ${ }^{35}$. Mediante el

\footnotetext{
31 "La cultura, que es la unción prodigiosa que distingue a un premio Nobel de un hombre de Cromagnon, ¿a quién se debe? No a la masa, sino al individuo eminente. El descubridor de la chispa de pedernal fue un individuo superior, como Edison o Marconi. Unos cuantos millares de sujetos excepcionales han llevado a la especie humana desde la miseria, la mortalidad y la rudeza de la prehistoria hacia el consumismo, la longevidad y el refinamiento". G. Fernández de la Mora, "La minoría es la clave", $A B C$ de $18-X I I-1980$.

${ }^{32}$ G. Fernández de la Mora, "Los mansos", $A B C$ de 20-II-1965.

${ }^{33}$ Op. cit., p. 255.

34 "Este hecho demuestra que la objetiva racionalización de la vida humana no puede producirse por la racionalización subjetiva de todas las decisiones de cada uno, sino por la racionalización de la información, de los saberes, de las técnicas y de las normas, es decir, por la racionalización de las minorías creadoras y de las dirigentes". G. Fernández de la Mora, "Sobre lo irracional", Razón Española, 7, 1984, p. 271.

35 "Pero los grandes progresos los llevan a cabo investigadores que se plantean problemas irresolutos y genéricos que no les atañen tanto en cuanto vivientes, como en cuanto científicos. Es en ese
} 
uso de la razón las minorías agrandan el acervo cultural y su labor es creadora respecto a estos productos. Se trata de una aportación al corpus de productos culturales, una nueva objetivación de la razón y, en definitiva, una creación que no se limita, simplemente, a utilizar las razones y prótesis culturales ya existentes.

La acción de las masas es, por tanto, de consumo que mantiene "ociosa la propia razón personal" 36 . Se trata de un uso intermitente y condicionado de la razón causado por pereza, prisa, cálculo o miedo ${ }^{37}$. La vida está marcada por el pragmatismo y, ante todo, por la inercia que supone la aceptación acrítica de los postulados de unos pocos. A la masa pertenecen la mayor parte de la humanidad ${ }^{38}$. La actitud de la masa es el conformismo y la búsqueda de lo fácil, frente a la dificultad que supone el ejercicio de la razón ${ }^{39}$. Con esto no se indica que la masa, el hombre medio, no es capaz de la razón, es decir, que el hombre-masa, apelando a la terminología orteguiana, es irracional. Se trata más bien de una falta de voluntad por parte de la masa, de un cierto desprecio de la razón o, al menos, de una opción de vida basada en la comodidad. Comodidad que se complementa con un cierto desprecio hacia la labor de la minoría, hacia la especulación pura ${ }^{40}$. La masa no sólo es reacia al uso de la razón sino que, además,

Esta relación producción-consumo establecida entre la masa y la minoría razonadora destaca la importancia de las elites. Son ellas las que dirigen el avance de la sociedad y de ellas depende el progreso social y cultural de un determinado grupo humano y de la Humanidad en general. Por ello, las minorías, además de aparecer tras gran esfuerzo y no ser un producto de la improvisación, son el bien social más escaso, un bien que hay que promocionar y valorar so riesgo de perecer. En definitiva, es de estas minorías de las que depende el destino de un país y éste se hace más grande cuanto más adecuado trato dispensa a sus minorías ${ }^{41}$.

nivel donde la razón es estrictamente creadora". G. Fernández de la Mora, "La razón creadora", Razón Española, 86, 1997, p. 258.

${ }^{36}$ Ibidem, p. 258.

${ }^{37}$ Ibidem, p. 262.

38 "La inmensa mayoría de la Humanidad no es productora sino consumidora de los hallazgos de unos pocos". G. Fernández de la Mora, "La universidad, amenazada", $A B C$ de 24-IV-1981.

39 "Por el contrario, el gregarismo o es la respuesta pragmática del escéptico, o es la actitud débil de quien no es capaz de raciocinar y enfrentarse con una ideología preponderante o con una moda. En el conformismo hay docilidad y cansancio". G. Fernández de la Mora, "Razón y adaptación", Razón Española, 44, 1990, p. 274.

40 "El hombre masa siente un cierto desprecio hacia la especulación pura. Por eso suele ver al teórico bajo las imágenes caricaturizantes del sabio distraído y del bizantinismo". G. Fernández de la Mora, "Maeztu, razón de la victoria", $A B C$ de 4-V-1974.

41 "Los pueblos se engrandecen cuando son decididamente promotores, conservadores y usuarios de sus minorías". G. Fernández de la Mora, "Relevo generacional”, ABC de 24-III-1981. 


\section{Imperativo de selección: minorías, ideologías y democracia}

La esencial composición elitista de la sociedad es concretada por Fernández de la Mora con el concepto de razón. Será este atributo el que alinee a los individuos en masa o minoría según sea el ejercicio racional de cada uno. A esta afirmación factual, Fernández de la Mora, añade una normativa. Si toda sociedad es eminentemente elitista, es decir, se divide entre minorías y masas, y de esas minorías depende el bienestar y el progreso de la sociedad toda, es necesario, y aún vital, orquestar el mejor método para elegirlas. Se impone, pues, un "imperativo de selección”, expresión ésta de indudable eco orteguiano ${ }^{42}$.

$\mathrm{Al}$ igual que en Ortega las elites no son exclusivamente políticas, aunque Fernández de la Mora aplica preferentemente el imperativo de selección al ámbito de la política. Y es que la importancia del "imperativo de selección", fundamental en todo ámbito, se acentúa en cuanto a las elites políticas se refiere. Principalmente, porque el circunstancialismo de Fernández de la Mora, es decir, el hecho de que cada circunstancia histórico-social reclama un tipo de medidas políticas concretas, no permite extrapolar esquemas ajenos ni importar elites dirigentes. Los dirigentes tienen que provenir del propio cuerpo social. De ahí que el método de selección sea fundamen$\operatorname{tal}^{43}$. De este dependerá la composición de la elite dirigente y, a la postre, el futuro de la sociedad. Pero, además, toda comunidad humana ha de dotarse con las minorías más adecuadas, los efectivamente mejores razonadores. Facilitar el ascenso de las elites indicadas significa el éxito, mientras que la dotación de una elite política de dudoso valor significa un proceso involutivo y un deterioro social.

"Pero no es la obra de una razón colectiva, disuelta igualitariamente en una masa, sino de la razón de unos pocos, capaces de prever, de inventar y de arbitrar soluciones adaptadas a las circunstancias. Esos son los egregios, los que se salen de la grey para pensar e innovar en vez de representar y repetir. El sentido y el ritmo del progreso histórico no dependen de las muchedumbres aunque totalicen millares de millones de personas; dependen de los que las orientan. Lo decisivo es que las elites tengan razón y, cuando un pueblo se da unos dirigentes que la tienen en muy escasa medida, esa comunidad, en vez de enriquecerse en bienes y en valores, se deteriora económica y moralmente. Es lo más involutivo que puede acontecerle a una sociedad" ${ }^{44}$.

La elite política es especialmente susceptible de no ser aristocrática. No hay nada que garantice que quien está en el poder sea minoría razonadora salvo la orquestación

\footnotetext{
42 J. Ortega y Gasset, España invertebrada, Madrid, Austral, 2007, p. 134-140.

${ }^{43}$ G. Fernández de la Mora, "La minoría es la clave", $A B C$ de 18-XII-1980.

${ }^{44}$ G. Fernández de la Mora, "Dintel”, Razón Española, 1, 1983,p. 4.
} 
de un método de selección adecuado para evitar una selección invertida, es decir, una selección al margen del criterio aristocrático. La existencia de una elite política no garantiza la presencia del elemento aristocrático en ella.

La ausencia de una identificación de la elite política con la minoría razonadora o aristocracia se ejemplifica en el hecho de que puede haber una elite política desaristocratizada y muestra los riesgos que la esfera política tiene. Esta elite, la dirigente política, en ese momento se despoja de los dos principales atributos de la aristocracia, es decir, de las ideas, el uso de la razón, y el coraje. La masificación de las elites se produce por la avidez de poder, por la voluntad de mando.

\begin{abstract}
"Hay, en segundo lugar, las élites oportunistas, que aspiran al mando por el mando, que rehúyen el riesgo y que adoptan las posiciones que en cada coyuntura consideran con más posibilidades de triunfar o de premiar la adhesión. Este practicismo, acobardado y teóricamente vacío, se ha adueñado de una gran parte de la clase política occidental y es uno de los síntomas más claros de la crisis intelectual y moral de nuestra cultura. Una élite sin coraje y sin ideas está mentalmente masificada, no conserva de aristocracia más que la jerarquía física: pero le falta el más noble elemento, que es una filosofía. De ahí su versatilidad, su fragilidad y su ineficacia" 45 .
\end{abstract}

Las elites, por tanto, se pueden masificar. No hay, en Fernández de la Mora, algo parecido a una estática social férrea en la que las clases sean similares a castas. La dinámica social impone la posibilidad de la decadencia y el cambio. Así las minorías que esforzadamente se autoseleccionan, se pueden igualmente enajenar en el momento en el que se rigen por criterios no aristocráticos. Si, además, como se ha señalado, el elemento distintivo de las aristocracias es el uso de la razón, la búsqueda del poder corrompe el elemento aristocrático. El razonador puede desaristocratizarse poniéndose al servicio de una causa política con vistas a lograr el poder. En ese momento, se convierte en un "intelectual conformista" y en "híbrido de investigadores y políticos". Les faltan ideas, rigor y les sobra voluntad de dirigirse al vulgo ${ }^{46}$. Les falta la soledad característica del aristócrata, de aquel que se dedica a una actividad compleja siendo, por tanto, comprendido por pocos. Masificación y aristocratismo son términos antagónicos. Por ello, la voluntad política, de poder, que requiere la proyección pública implica necesariamente masificación.

Aparece aquí el fenómeno ideológico y la crítica de Fernández de la Mora a la ideología. La vulgaridad inherente a la ideología no sólo contradice los hechos (el consustancial elitismo) sino que además contribuye a la corrupción de las aristocracias que son, al fin y al cabo, el motor social. La masificación ideológica no es sólo, por

\footnotetext{
${ }^{45}$ G. Fernández de la Mora, "Versatilidad", $A B C$ de 13-VIII-1978.

${ }^{46}$ G. Fernández de la Mora, "El intelectual conformista", $A B C$ de 11-III-1982.
} 
tanto, teóricamente y tácticamente incorrecta sino que, además, es socialmente nociva y disfuncional. El intelectual ávido de poder abandona el elemento aristocrático, cede su particular trato con las ideas para plegarse a las consignas partidarias ${ }^{47}$. El público objetivo determina el mensaje y su autor, el "intelectual conformista", pierde tanto las virtudes intelectuales (rigor, revisionismo de las ideas, objeción constante a los postulados), como las morales (coraje, sinceridad, desinterés). El intelectual espurio, masificado, o, como él lo denomina, intelectual "impuro" 48 se caracteriza por su voluntad de poder $^{49}$. ¿Cómo se produce la masificación de las minorías que tan grandes desgracias puede traer a una sociedad $?^{50}$ Varios son los fenómenos que implican la búsqueda del poder por parte del intelectual, con su consiguiente masificación.

En primer lugar, y quizá el principal fenómeno, es el conformismo y el seguidismo, es decir, la pérdida del carácter creador propio de la minoría. Este fenómeno se produce cuando el intelectual, volcado hacia el poder político, se limita a la repetición de las consignas políticas. Una de sus acciones típicas suele ser la simple firma de manifiestos, movidos por el cansancio ${ }^{51}$. Sustituye los razonamientos originales por esquemas diseñados para ganarse el favor de la masa. En eso consiste la disolución del intelectual, que pliega su pensamiento a la situación ${ }^{52}$. Plegamiento éste que consiste en obtener mayores réditos electorales. Esta dinámica hace del intelectual algo inauténtico y bastardo de la corrección política y la ideología y apartado de su capacidad creativa ${ }^{53}$. Es así que la separación entre minoría y masa se disuelve ya que el intelectual se limita a la repetición de aquello que está en la mente de la masa o en la del poderoso. El intelectual abandona la pregunta fundamental por la realidad y trata

\footnotetext{
47 "El área de la lucha por el poder es siempre intelectualmente sospechosa por su escasa objetividad y su constitutiva inclinación a la manipulación verbal y factual”. G. Fernández de la Mora, "Razón y progreso", Razón Española, 68, 1994, p. 258.

${ }^{48}$ Cf. G. Fernández de la Mora, Pensamiento Español 1964, Madrid, Rialp, 1965, p. 13.

${ }^{49}$ De esta manera el pseudointelectual cultiva más la voluntad que la razón. G. Fernández de la Mora, "El intelectual y la razón", Razón Española, 15, 1986, p. 5.

${ }^{50}$ En el caso de España, Fernández de la Mora afirma que la tardía industrialización tiene su origen en la vocación política de los intelectuales. Su vuelco hacia lo público habría dejado desiertos los ámbitos científico-técnicos necesarios para el giro industrializador. G. Fernández de la Mora, "1868: un tren perdido", $A B C$ 7-XII-1968.

${ }^{51}$ G. Fernández de la Mora, "Un negro de Carlos V", $A B C$ de 13-II-1958.

52 "La disolución del intelectual no reside tanto en el agnosticismo y en el relativismo cuanto en las adhesiones flexibles y gregarias al producto del día". G. Fernández de la Mora, "Los mansos", $A B C$ de 20-II-1965.

53 "En el ámbito intelectual, aparecen el que escribe para realizarse y ser él mismo, y también el otro que lo hace para situarse. Estos últimos se pliegan al pensamiento único, a la corrección política, a las modas, a la ideología dominante, piensan para estar según los que están, se mueven al margen del genuino ser". G. Fernández de la Mora, "Razón de ser”, Razón Española, 108, 2001, p. 5.
} 
de buscar aquellas consignas que le proporcionen mayores réditos políticos ${ }^{54}$. El salto de la corporación científica a la esfera pública requiere el abandono del rigor y la voluntad creadora. Así, el intelectual que abandonando su quehacer, y movido por la voluntad de poder, salta a la esfera política bajo el palio de una determinada ideología, que no es creación suya, "renuncia a ser auténtico y se convierte en un repetidor o en un glosador" 55 . Y así abdica de su función creadora, lo que supone, a la luz del papel del individuo egregio en Fernández de la Mora, una auténtica amenaza para toda la Humanidad ${ }^{56}$.

¿Está Fernández de la Mora excluyendo tajantemente la posibilidad de que el intelectual genuino participe en la política? Rotundamente no. Su ejemplo vital lo hubiera desacreditado para semejante afirmación. Pero la labor práctica política es diametralmente opuesta a la actividad especulativa del razonador. El intelectual puede participar en política pero para evitar la masificación tiene que mantener su rigor y originalidad, es decir, no debe apelar a las ideologías. Además ha de tener conciencia de que su acción va a estar guiada por cierto nivel de compromiso, un acople de su labor práctica respecto a las necesidades prácticas del Estado ${ }^{57}$. Cuando un intelectual entra en la esfera de poder sufre una doble tensión entre la politización y el bizantinismo que debe saber gestionar para no masificarse ${ }^{58}$.

En último lugar, en cuanto a la masificación de la minoría, ésta se puede dar por la pérdida de ejemplaridad de las elites. Cuando éstas abandonan su función de ser arquetipos sociales se masifican. Y esto ocurre cuando en lugar de proponer como deseables los valores propios de la aristocracia, proponen la degradación o la pérdida de nobleza. Cuando esto ocurre, cuando las minorías renuncian a ser ejemplares de lo mejor, no sólo abdican de su propia condición sino que cometen un crimen con respecto al resto de la sociedad ${ }^{59}$.

Las ideologías, por tanto, suponen una disolución de la aristocracia, aunque como en toda sociedad se siga dando una estructura oligárquica o elitista. Las ideologías,

\footnotetext{
${ }^{54}$ Cf. G. Fernández de la Mora, “Tener razón”, Razón Española, 6, 1984, p. 130.

${ }^{55}$ G. Fernández de la Mora, "Razón y compromiso", Razón Española, 36, 1989, p. 4.

56 "Lo que amenaza a la Humanidad actual, especialmente a la de Occidente, no es la veloz carrera de las ciencias, es la traición moral de los intelectuales, su abdicación de la razón práctica creadora". G. Fernández de la Mora, "La razón creadora", Razón Española, 86, 1997, p. 260.

57 "Quienes por vocación o por imperativos de las circunstancias bajan al ágora, si son sistemáticos y fuertes pueden conservar todas sus convicciones, pero han de renunciar a que prevalezcan, enterizas, en la actuación del Estado". G. Fernández de la Mora, "El taifismo", $A B C$ de 11-XI-1977.

${ }^{58}$ G. Fernández de la Mora, "La lección bizantina", $A B C$ de 25-VI-1954.

59 "Las minorías traicionan a la especie cuando, en lugar de orientarla al señorío del ánimo para la consecución esforzada y progrediente de los valores, la invitan a la rebeldía universal, a la alienación y a la degradación". G. Fernández de la Mora, "Hacia abajo", ABC de 18-XI-1975. En este texto Fernández llega a denominar a esta acción: "delito de lesa humanidad".
} 
en lo que tienen de simplificación de las ideas y de atención a intereses no estrictamente racionales, son incompatibles con el aristocratismo. De ahí que el intelectual que se pliega a los dictados ideológicos no sea sino un pseudointelectual. Una sociedad en la que prima el ideologismo tiene pocas posibilidades de dotarse de una elite dirigente realmente aristocrática. Nuevamente aparece la necesidad de un imperativo de selección, de orquestar un ordenamiento jurídico-político que facilite el acceso de las minorías aristocráticas al poder ${ }^{60}$.

La consideración del elitismo, la alabanza de las minorías y el carácter imperativo de la selección, unido a la consiguiente masificación de las minorías de las ideologías, contiene como corolario una crítica a la democracia inorgánica ${ }^{61}$. El riesgo de la separación entre elite fáctica y esencial aristocratismo, ideas y coraje, se acentúa, en opinión de Fernández de la Mora en la democracia inorgánica.

En la democracia inorgánica la aristocratización no parte de una elección personal sino que depende de una elección popular. En ese caso no es ya la elite la que se autoselecciona por su aristocratismo sino que es sujeto de valoración por parte de una masa ¿Cómo puede una masa que es extraña a los valores aristocráticos elegir a los miembros de la elite? La democracia inorgánica apelando al concepto de "representación" contradice la natural estructura elitista de toda sociedad. Lo hace porque, dado que toda sociedad tiene una estructura diádica, gobernantes y gobernados o elites y masas, la minoría dirigente no puede ser simplemente una representación de la masa. Si así fuera, dejaría de ser elite y esto facilitaría el ascenso no de los mejores sino de los más mediocres ${ }^{62}$. Fenómeno este que sería disfuncional y conllevaría el progresivo estancamiento y disolución social.

Y es que, siguiendo a Schumpeter, Fernández de la Mora considera a la democracia como una estructura procedimental de selección de elites dirigentes. Así pues, la democracia no se puede imponer como imperativo moral sino que, de hacerlo, será por ser el mejor sistema para elegir a los mejores, a las elites más adecuadas. Es decir, el mejor para cumplir con el imperativo de selección. La democracia sigue siendo netamente oligárquica ${ }^{63}$.

\footnotetext{
${ }^{60}$ Como comentaremos más adelante, el sistema de Fernández de la Mora supone una fusión de la autoridad y la potestad. El imperativo de selección supone la subsunción de la potestad en la autoridad. ${ }^{61}$ Utilizamos aquí la terminología utilizada por los partidarios, como Fernández de la Mora, de la democracia orgánica o corporativa para referirse a la democracia liberal.

62 "Los gobernantes deben ser los mejores y, por tanto, muy superiores a la media general. Si fueran una fiel reproducción del hombre masa que los vota no serían una élite. Contrariamente a lo que supone la teoría demoliberal, lo importante no es que el gobernante sea representativo, sino que sea selecto". G. Fernández de la Mora, "Neocorporativismo y representación política", Razón Española, 16, 1986, p. 144.

63 "La democracia real es una oligarquía, elegida por votación popular". G. Fernández de la Mora, La partitocracia, Madrid, Instituto de Estudios Políticos, 1977, p. 47.
} 
La teoría elitista niega la democracia ideal. Es decir, la teoría de la democracia que no se asimila a la realidad de este régimen. En definitiva, Fernández de la Mora no critica la democracia inorgánica per se sino que su ataque se dirige hacia la ideología democrática. Sin embargo, lo que demuestra el funcionamiento real de la democracia es que, incluso, su viabilidad no depende tanto de las masas, como afirma, sino de la disposición de las elites que la componen. La democracia, como toda forma de gobierno, depende de su minoría dirigente. De ahí que la ficción representativa, la apelación a la soberanía del pueblo y su imposición moral no sean sino aspectos meramente ideológicos. La democracia es, de entre muchas, un sistema técnico de elección de elites y como tal, moralmente neutra.

"El aceptable funcionamiento de la democracia inorgánica no está condicionado por factores tan rígidos como la infraestructura económica o la psicología nacional; más bien depende de unas ciertas disposiciones de la clase política. Aunque resulte paradójico para quienes ignoran la teoría elitista de la sociedad, también la viabilidad del modelo democrático depende principalmente de la minoría"64.

Incluso, la aparición de la democracia de masas, la irrupción masiva del pueblo en la esfera pública fue obra de una minoría. Fue la burguesía la que la introdujo para disputarle al rey y la aristocracia nobiliaria la hegemonía política. Fernández de la Mora señala que incluso la fracción de la sociedad, necesaria para la democracia inorgánica, es un hecho artificial causado por las elites ${ }^{65}$.

Mediante esta crítica Fernández de la Mora pretende desmitificar la democracia inorgánica, situarla en su justo lugar que es el de los múltiples sistemas electivos. La democracia es un medio al servicio del verdadero fin que es la selección de la minoría dirigente.

\section{Conclusión}

En conclusión, para Fernández de la Mora toda sociedad se estructura en torno a dos grupos: las masas y las minorías. Su concepción de la sociedad, y de la historia, es claramente elitista y aristocrática. Toda organización, y relación social, se da como una relación entre individuos egregios y hombres medios. La desigualdad es, por tanto, uno de los elementos configuradores de la sociedad.

El elemento sobre el que gira la principal desigualdad social y antropológica es, sin duda, la razón. La clase aristocrática se caracteriza por un mayor uso de la razón que, a la luz de la naturaleza del hombre, requiere asimismo una decisión de tipo

\footnotetext{
${ }^{64}$ G. Fernández de la Mora, "Minoría y democracia", $A B C$ de 5-IV-1977.

${ }^{65}$ G. Fernández de la Mora, "La envidia, factor político", Razón Española, 4, 1984, pp. 429 y ss.
} 
moral. La vía intelectual es ardua y costosa por eso el razonador al elegir este tipo de vida se auto impone el imperativo de ser mejor, de ser más. Por eso, la minoría adopta un tipo de vida superior desde el punto de vista moral. Así, se separa en cuanto a su actividad, uso de la razón, y en cuanto a su actitud frente a la vida. Frente al carácter acomodaticio de la masa, la minoría se hace exigente consigo misma en busca de la excelencia.

Excelencia de la que depende no sólo su propio estatus de dominación sino también el progreso de toda la sociedad. La masa es esclava de la función creadora de la minoría. Los individuos egregios son los protagonistas de la historia en general y del progreso de cada sociedad. La labor de la minoría es necesaria para el bienestar de toda comunidad, de ahí que sea fundamental la selección y promoción de los mejores. Esta selección y promoción son funcionales desde el punto de vista social en la medida en que son las minorías las que elevan el nivel de la existencia de los grupos. Un pueblo caracterizado por el establecimiento de un sistema adecuado de jerarquías y que promueva la docilidad de las masas y la ejemplaridad de las minorías es no sólo más sociedad, estructuralmente hablando, sino también está abocado a un progreso mayor. Por eso es necesario un "imperativo de selección”, un sistema por el que la sociedad aúpe a los puestos dirigentes a las minorías razonadoras. Una sociedad con un adecuado sistema selectivo es una sociedad sana y pujante.

¿En qué afecta la concepción elitista de la sociedad a la doctrina de las ideologías? La relación inversamente proporcional entre ambas es obvia. Las ideologías son vulgarizaciones de argumentos racionales (filosofías políticas), por tanto, supone una masificación de los mismos en la medida en que los adaptan al criterio de las masas. Pero, además, es dudoso que las ideologías sean un buen sistema para incentivar la selección, especialmente, si se tiene en cuenta que éstas, las ideologías, facilitan la masificación de la minoría. Por su propio carácter la ideología es masificadora tanto para la masa, como para la minoría.

¿Implica esto que el imperio de la ideología supone un cambio de paradigma social, una ruptura de la jerarquía social, una igualación? De ninguna manera. Incluso en un sistema tan aparentemente igualatorio como es la democracia inorgánica la oligarquización es palpable. Por tanto, parece obvio que las ideologías más allá de ser disfuncionales socialmente hablando, son falsarias. Y lo son porque tienden a ocultar el carácter oligárquico y elitista de toda forma de sociedad. Es aquí donde el término ideología adquiere un tinte maquiavélico que, por cierto, no es explícitamente mencionado en la definición canónica que proporciona Fernández de la Mora. Las ideologías tratan de legitimar un sistema de selección falso, en el que los ideólogos ávidos de poder se auto justifican por encima de los legítimos aristócratas, y lo hacen degenerando así las estructuras sociales.

Las ideologías son vulgarizadoras y tratan de omitir el consustancial aristocratismo de toda organización social resultando así falsas y disfuncionales. Sin embargo, 
incluso las formas políticas en que las ideologías se encarnan, desde regímenes políticos hasta formas institucionales de la ideología, muestran este esencial elitismo. Así se demuestra que la ideología es una ocultación de la adecuada jerarquía social o una transmutadora de las minorías razonadoras, las únicas legítimas, en minorías retóricas cuya superioridad estribe en la capacidad de movilización social. En este caso la supuesta elite, la oligarquía partidaria o los ideólogos, son tan masa como aquella sobre la que pretenden gobernar. De ahí que el carácter vulgar de la ideología sea un peligro y un falseamiento de la realidad. 